\title{
ПОЛИТИЧЕСКАЯ ИДЕНТИЧНОСТЬ ЕС: НОВЫЕ ПАРАДИГМЫ И СТАРЫЕ ПРОБЛЕМЫ
}

\begin{abstract}
Аннотация. Статья посвящена анализу спорных вопросов в концепции европейской политической идентичности. Рассмотрены аспекты достижения ЕС единого политического и географического измерения. Анализируются причины отсутствия признания членами ЕС общего согласованного понятия идентичности и представления об общем будущем сообщества. Автор показывает, что в основе формирования европейской идентичности лежат концепции центральности индивида в обществе и христианства как модели цивилизационного развития и социокультурной интеграции. Сущность объединённой Европы не только плюралистическая, а универсалистская, поэтому необходимо переосмыслить природу Европейского Союза.
\end{abstract}

Ключевые слова: Евросоюз, политическая идентичность, постнациональное государство, Центрально-Восточная Европа, миграционные процессы, христианство, Конституция ЕС.

Рассмотрение затянувшегося общеполитического кризиса, который уже несколько лет переживает Старый Свет, предполагает изучение динамики обретения Европейским Союзом собственного политического измерения.

Роль Европы в международных процессах в течение последних ста лет коренным образом изменилась. С наступлением "краткого века" Западная Европа по мере того, как исчерпывала свою общепризнанную цивилизационную миссию, создавала и новую культуру международных отношений [Борко, 2003: 15; Загорский, 1999].

Идея единой Европы, связанная со стремлением добиться глобального справедливого управления европейскими странами, вышедшими из двух мировых войн, привела к новому состоянию межгосударственных отношений и породила особый субъект - Евросоюз. Создание Европейского сообщества и его дальнейшее развитие, в свою очередь, сопровождались переосмыслением прерогатив народов и стран входящих в него на основе общерегулятивного принципа наднациональности.

Формирование общеевропейского мировоззрения и общеевропейских ценностей, в результате появления европеизма в качестве альтернативной философии

(C) Алонци Роберта - PhD по истории и международным отношениям, ассоциированный профессор, доцент Флорентийской Высшей школы переводчиков (Италия), приглашенный преподаватель НИУ ВШЭ, аспирант кафедры сравнительной политологии РУДН. Aдpec: Россия, Москва, ул. Миклухо-Маклая, 17/1, E-mail: alonziroberta@gmail.com

DOI: http://dx.doi.org/10.15211/soveurope62018142151 
национализму XIX и первой половины XX веков [Буховец, 2008], стало главным фактором претворения в жизнь идей, на которых основан европейский проект [Вайнштейн, 2009]. Однако со временем вопрос конструирования политической идентичности ЕС начал сталкиваться с теми принципами и факторами, на которые опирался процесс евроинтеграции, в том числе принципом европейского политического и географического единства, а также темы христианства как фактора цивилизационного развития и социокультурной интеграции.

\section{Принцип европейского политического единства и осуществление перехода к постнациональному государству}

Политически Европа представляла собой многообразное сообщество, в котором сосуществуют разнообразные интересы, устремления и различное отношение к существующей действительности. Тем не менее, в любую эпоху истории Европы предпринимались попытки придать этой бесформенной массе разных интересов, устремлений и подходов свойства политической единицы.

Процесс осуществления идеи объединенной Европы на более высоком уровне политической интеграции представлялся приемлемым исключительно при укреплении прерогатив национального государства. Государство рассматривается при этом как ядро своеобразных социальных совокупностей, идентичность которых проявляется в реализации идеи нации и утверждении собственного суверенитета.

Маастрихтский договор, согласно которому был создан Европейский Союз, закрепляет превосходство утилитаризма над всеми иными идеями. Идеологическое содержание интеграционного процесса сведено к более прагматичной идее о том, что общественная европейская наднациональная структура действует как общий регулятор, корректируя недостатки национальной политики отдельных европейских стран [Taylor, 1996: 54]. Амстердамский договор о внесении изменений в Договор о Европейском Союзе был подписан в 1996 г. с надеждой “усовершенствовать" Европу для европейцев, но эта цель осталась на уровне декларации. Аналогично Европейская Конституция, подписанная в Ницце в 2000 г., не обрела действенного правового статуса [Кавешников, 2004/2005; Борко, Буторина, 2001].

Интересно заметить, что на этом фоне Германия стала первым примером постнационального государства, которое отклонило национализм как регулятивный принцип, не отказываясь при этом от своей концепции объединенной Европы [Kirchner, 1993: 147; Pond, 1992: 114].

Судебное решение Федерального Конституционного суда Германии 1993 г., в котором был поставлен вопрос о конституционности Маастрихтского договора, подтвердило, что ЕС осуществляет только те полномочия и компетенции, которыми его наделили государства-члены. Относительно Экономического и валютного союза (ЭВС) Конституционный суд постановил, что Германия после ратификации договора не должна рассматривать как необратимый процесс перехода к валютному союзу. Он подтвердил право на выход страны из Евросоюза, если будет доказано, что желанная экономическая стабильность не достигнута (закладывая, таким образом, теоретические основы возможного будущего “германэкзит”) [Di Gaspare, 2012: 390]. Это решение Федерального Конституционного суда Германии повлекло за собой приостановку строительства федеральной Европы. Процесс подготовки 
договора, который заменил Маастрихтский договор, был самым длинным в истории ЕЭС/ЕС.

В 2009 г., отвечая на поставленный вопрос о конституционности Лиссабонского договора и опираясь на заключение в постановлении по Маастрихтскому договору, Федеральный Конституционный суд Германии подтвердил, что ЕС является "Staatenverbund", а именно союзом государств, в котором они остаются "обладателями договоров" [La sentenza...]. Союз не обладает реальным суверенитетом, но просто “автономией принятия решений”, вытекающей из воли государств-членов.

В общих чертах как в прошлом одной из главных функций европейской интеграции было управление процессом восстановления роли Германии в Европе, так в 1990-х годах процесс евроинтеграции стал рассматриваться как средство избежать новой немецкой гегемонии в ЕС после объединения Германии [Romano, 1994: 53; Ferraris, 1998: 183; Feltri, Sangiuliano, 2015]. Экономический кризис, переживавшийся государствами объединенной Европы, выдвинул на первый план и расширил влияние на процесс принятия решений небольшого круга лидеров-технократов, которые в ФРГ находятся под руководством Ангелы Меркель. Это означает явный поворот к федерализму не государств, а скорее государственных руководителей.

В такой (межправительственной) Европе нет “политики” в полном смысле этого слова (т.е. отсутствует поиск решений, основанных на широких эпистемиологических данных и ценностях, а также внимание к достижению консенсуса и опора на всеобъемлющую легитимность) [Ferrera, 2014], но имеется лишь совокупность дипломатических переговоров и достижения компромиссов с помощью заумных игр власти.

\section{Восстановленное географическое единство Европы. Проблемы миграции и европейская идентичность}

Окончание холодной войны и распад СССР открыли новую фазу ознаменовавшуюся расширением границ Европейского Союза на Восток [Глинкина, Луконин, 2002; Хижный, 2006] одновременно с расширением НАТО.

Процесс вхождения восточноевропейских стран в ЕС совершился, как считают многие эксперты, в связи с “исторической неизбежностью” их “возвращения в Европу". Начиная с эпохи после Второй мировой войны, определение того, чем должна быть европейская цивилизация, зависело от эволюции конфликта Восток-Запад, и было связано с противостоянием двух представлений о будущем развитии человеческого сообщества [Ferraris, 1999:14]. С падением Берлинской стены страны Центрально-Восточной Европы вошли в состав Европы, отличающейся от той, из которой они вышли, когда они находились на острие борьбы между Западом и Востоком.

Евросоюз пока не гарантирует создание настолько близких друг другу национальных сообществ, чтобы обеспечить социальную общность, в которой страны Востока Европы нуждаются [Waldemberg, 1998]. Путь интеграции стран Восточной Европы предполагает два основных этапа: переход от преобладания политики, в центре которой стояли главным образом интересы государства, и при этом проявление большего внимания к индивиду [Genov, 1998], а также связанный с этим переход от национализма к наднациональности. Отсутствие общей воли в осуществлении такой линии сопровождается противоположной тенденцией к централизации "абстрактных" для жителей ЕС европейских учреждений. Процесс конструирова- 
ния политической идентичности ЕС реализуется путём укрепления наднациональности, или же посредством самоограничения суверенитета национального государства, но такой степени самоопределения Восточная Европа ещё не достигла.

Отсюда следует, что проект “возвращения в Европу” выполним только при реализации требуемых в этих странах социо-экономических реформ. Однако, вместо того, чтобы вернуть странам Центрально-Восточной Европы самостоятельность, особенно экономическую, руководящие органы ЕС проводят линию, которая по сути лишает их самостоятельности и усугубляет их разрыв с развитыми странами Западной Европы. И это, с одной стороны, превратило восточноевропейские страны в пассивные “экспортные рынки и резервы дешевой рабочей силы” [Leoncini, 2011] с другой, - в чистые получатели кредитов ЕС.

В 2006-2014 гг. страны Восточной Европы получили около 175 млрд евро из фондов ЕС, это гораздо больше, чем их вклады в ЕС. Польша, в частности, была основным чистым бенефициаром с активным балансом, составляющим 76,3 млрд евро. За ней следовала Венгрия - 27,3 млрд евро. Только в 2014 году Варшава получила из Брюсселя 13,7 млрд евро, что составило 3,47\% её ВВП. В том же году экономический баланс Венгрии, возглавленной Виктором Орбаном, спорным для ЕС политиком, оказался столь же прибыльным - 5,6 млрд евро, т.е. 5,64\% ВВП. Субсидии от ЕС Чешской Республике составили 3 миллиарда евро в год, 2\% ВВП, Болгарии 1,8 млрд, 4,4\% ВВП, Литве 1,5 млрд, 4,3\% ВВП, Латвии 799 млн, 3,35\% ВВП [D’Argenio, 2016].

Восточные страны вошли в Европейский Союз с целью "освободиться от советского прошлого" и примкнуть к “атлантизму". Эти страны претендуют на главную роль, вместе с Соединёнными Штатами, в поражении "коммунизма" и отстаивают свое естественное и неоспоримое право на членство в ЕС. Они исходят из того, что это же они, а не “старые европейцы”, являются носителями конституционных и основополагающих ценностей новой постбиполярной Европы, хотя они и не стремятся полностью разделять европейские ценности [Bruzzone, 2014].

Правительство Польши, например, выступает против идеи создания многоскоростной Европы. Причём национализм и популизм в Польше растут. Тем не менее, внешняя политика Польши преследовала цель расширения границ ЕС до Украины. European Foreign Policy Scorecard 2015 г. показал, как Польша сыграла решающую роль в формировании реакции членов ЕС на действия России на Украине, особенно на начальном этапе конфликта. Она занимала первый ряд в числе стран, требовавших более решительного ответа ЕС на “аннексию” Крыма, и без колебаний поддержала санкции против России, несмотря на то, что сама понесла при этом заметные экономические убытки, особенно в том, что касается экспорта в Россию продукции польского сельского хозяйства [Buras, 2015]. В отличие от государств Восточной Европы, лишь недавно вступивших в ЕС, некоторые западные страны (например, Италия) занимали при этом более умеренные позиции, хотя “солидарность" с органами ЕС в Брюсселе заставляла их голосовать за применение и потом продолжение данных санкций.

Отсюда следует, что восстановленное географическое единство Европы, обеспеченное расширением ЕС на Восток, не гарантирует единства взглядов, которое помогло бы преодолеть различия. Именно достижение такого сходства подходов и позиций представляет собой внутреннюю цель “проевропейского” проекта. Но при 
углублении противоречий между странами-членами это географическое расширение $\mathrm{EC}$, наоборот, становится дальнейшей помехой в укреплении его политического измерения.

Между руководящими органами в Брюсселе, западноевропейскими и восточноевропейскими членами ЕС очевидно чёткое расхождение по поводу существенных законодательных аспектов, касающихся общего будущего Европы. Речь идёт, например, о позиции, принятой Вышеградской группой стран по вопросу о противодействии нынешним миграционным потокам из стран Африки, Азии и Ближнего Востока [Потемкина, 2015].

Процесс миграции, особенно нелегальной иммиграции в страны EC, как раз представляет собой более трудно решаемый вопрос для объединенной Европы. Миграционные потоки достигли такой интенсивности, что связанные с ними перемены можно характеризовать как самую настоящую "революцию” [Любин, 2003; Потемкина, 2010, 2017].

В связи с этим раздаются призывы пересмотреть законодательную базу регулирования потока миграции в страны Евросоюза. Пока что это начинает делаться только в отдельных странах. Так, в Германии, принявшей на себя основную массу иммигрантов в 2014-2016 гг. смогла стать третьей политической силой в стране [Любин, 2018].

Аналогичные тенденции наблюдаются также в Австрии, где пришедшее к власти правое правительство ужесточило государственную политику противодействия нелегальной иммиграции, собирается применять ускоренную высылку на родину вновь прибывших иммигрантов.

Приступившее в июне 2018 г. к исполнению своих обязанностей новое правительство Италии, созданное двумя партиями - Движение 5 звёзд и Лига (ранее называвшаяся Лига Севера), в лице своего министра внутренних дел и лидера партии Лига М. Сальвини, ещё в ходе предвыборной борьбы заявлявшего, что он будет настаивать на скорейшей высылке из Италии нелегальных и не имеющих права находиться в стране иммигрантов, предложило парламенту утвердить новые законы, позволяющие проводить такую жёсткую линию.

\section{Христианский компонент европейской идентичности}

В основе формирования европейской идентичности лежат концепции центральности индивида в обществе и христианства как модели цивилизационного развития и социокультурной интеграции [Chabod, 1967: 30; De Rougemont, 1949: 13].

В целом отцы-основатели единой Европы исходили из своих представлений о государстве, законе, мире и ответственности, основанных на христианской вере. Они не строили конфессионального государства, но выступали за политику морального разума, христианства, не отчуждаемого от разума [Ratzinger, 2003: 89].

Ислам, как отмечает Папа Римский Бенедикт XVI, теоретически не противопоставляется христианству, но отрицает результаты нынешней секуляризации христианской Европы [Ratzinger, 2003: 89]. Не случайно нынешнее состояние дел с европейской идентичностью возникло после того, как её христианские корни были отвергнуты (как это произошло, когда в 2000 г. оказалась не принята Конституция в Ницце). Европейская конституция (Конституция ЕС), отрицающая “общие христианские корни”, фактически одобрила маргинализацию роли религии в культурном на-

Современная Европа, 2018, №6 
следии, убрав (во имя идеологического секуляризма) её основополагающий характер по отношению к процессу формирования общеевропейской идентичности.

В процессе секуляризации возникла тенденция относить религию к выбору самих индивидуумов за счёт сокращения и часто аннулирования характера религии как феномена нации. Это явление характерно для протестантских стран, но оно растёт и в странах католических. В них отношение к религии тоже изменилось. Сегодня только $23 \%$ французов и $30 \%$ немцев считают христианскую религию важным элементом национальной идентичности. В Польше, где в 1991 г. католиками себя считали 96\%, сегодня относят себя к таковым 87\%. В Чешской Республике $72 \%$ жителей говорят, что они не связаны с какой-либо религией [Religious Belief...].

Потеря роли религии как объединяющего фактора является не только социологической или историко-философской проблемой, но и оказывает глубокое влияние на политику, которая уже не может в той мере, как это было ранее, опираться на религиозную идентичность. Также следует отметить, что, если, с одной стороны, католики более строго соблюдают религиозные обряды, чем православные, то с другой, православные считают, что религия определяет национальную идентичность. Во всех странах, где большинство составляют православные, в среднем 70\% населения придерживается мнения, что православие действительно является средством определения национальной идентичности своей страны [Religious Belief...].

\section{Перспективы достижения политической идентичности ЕС (межљу универсализмом и плюрализмом)}

На этом фоне, миграционные процессы не выглядят единственной причиной размывания паневропейских культурных и религиозных ценностей, но вносят новую переменную, усиливающую неизбежность определения материального и нематериального пространства осуществления законодательной деятельности ЕС.

Границы необходимы, и не только на институциональном уровне, но и на когнитивном. Они используются народами, чтобы определять своё поведение, представлять мир вокруг себя. Изменения границ отражают, в свою очередь, изменения в распределении и организации власти на территориальной основе [Diamanti, 2016]. Шенгенский договор открывает внутренние идеологические границы Европы и в то же время отменяет её внешние физические границы. Но нынешний кризис, связанный с невиданным притоком мигрантов и отсутствием консенсуса европейских стран в этом вопросе показывает, что при первенстве принципов наднациональности территориальные критерии никак не учитываются.

В современной политике приема и интеграции мигрантов находит отражение универсалистское призвание ЕС. Европейский Союз в свете требований федералистского космополитического европеизма стремится к принятию модели универсального гражданства, свободного от национальной принадлежности [Beck, 2000; Beck и др., 2007; Delanty, 2009; Schlesinger, 2007; Lo Schiavo, 2009: 16]. Согласно этому подходу, права вытекают не из суверенитета национального государства, а из “Конституции ЕС". Создание постнационального Европейского общего государства подразумевает переход от национализма к "конституционному патриотизму" [Hayward, 2007: 183; Mertens, 2007: 117; Muller, 2012; Maas, 2008].

Если идентичность всего Европейского континента определяется единым географическим пространством и общими макрокультурными чертами, то идентичность Европейского Союза определена только в политическом смысле. То есть пу- 
тем принятия его членами согласованного понятия идентичности и представления об общем будущем Сообщества.

Европейский Союз должен разработать принципы политического, социального, экономического и морального синтеза, согласно которым суверенные государства могут построить общий дом. Как считал Де Гаспери, строительство европейского единства не может быть ограничено его техническими аспектами. Тогда Европейское сообщество может превратиться в творение лишь специалистов технократов, не способных найти поддержку со стороны европейского населения [De Gasperi, 2009: 955].

Потеря легитимности, с которой сегодня сталкиваются европейские институты, является результатом долговременного процесса, начатого с постепенного и не слишком ощутимого разрыва между двумя измерениями, которые характеризовали европейский проект в духе отцов-основателей: идейно-политического и экономического. С падением “коммунизма" горизонты общественного строительства были омрачены иллюзиями, что объединение Европы может быть реализовано без учёта основополагающих политических принципов.

В условиях экономических и политических кризисов Европейский Союз больше не считается той величиной, которая способна поддержать мировое равновесие. Он воспринимается лишь как один из компонентов мирового порядка, включенный в круговорот “глобализации”. Уникальность и новизна европейского проекта уже не воспринимаются как таковые.

К тому же принятие в 2002 г. многими странами ЕС общей денежной единицы евро создало такую систему финансовых и экономических взаимосвязей, которые не сводятся лишь к собственным характеристикам (стран-членов и их межправительственных отношений), но обладают “автономной казуальной силой” [Prodi, 20141 в отношении политических структур. Всё это также оказывает значительное влияние на конструирование идентичности.

В этом контексте интересен также феномен брекзита [Громыко, 2016; Ананьева, 2016; Бабынина, 2016; Ананьева, Каневский, 2016]. Проблема с мигрантами в ЕС оказала решающее влияние на результат референдума в Великобритании и победу сил, настаивающих на выходе страны из ЕС. Но явление брекзита нельзя считать столь необычным для Европейского Союза. Традиционно Англия одновременно входит в европейское культурное пространство и является политическим аутсайдером сообщества европейских государств, так как сама по себе своим поведением, так сложилось исторически, исключает себя из европейской политики [Löwith, 1999: 6-7].

При отсутствии дополнительного способа интеграции, идея Конституции, опирающейся на “догму” плюрализма, становится основой “гражданской религии” европейской федерации. При этом Европа является культурно плюралистической, a Европейский Союз является также институционально плюралистическим её политическим выражением [Fabbrini, 2017]. Следовательно, сохранение различий является первым этико-практическим императивом ЕС. Но сущность объединённой Европы, не только плюралистическая, а универсалистская, поэтому необходимо переосмыслить природу Европейского Союза, отказаться от применяемой логики обобщения и притяжения.

Модель плюрализма, характеризующая институциональный подход к осуществлению этического измерения Европейского Союза, не может быть проявлением ни

Современная Европа, 2018, №6 
более сложного европейского культурного плюрализма, ни искусственной политической идентичности ЕС. Это всего лишь эпифеномен такой формы институционального учреждения, какую приобрёл Евросоюз. Но он не отражает точной естественной политической идентичности ЕС. Если в концепции плюрализма противопоставляется идея, что общество основано на фундаментальных ценностях, бесспорно разделяемых европейскими гражданами, то, учитывая сказанное нами ранее, это означает, что плюрализм представляет собой дополнительный фактор ослабления общеевропейской идентичности.

\section{Список литературы}

Ананьева Е.В. (2016) Мигранты в Европе. Великобритания // Современная Европа. № 2 (68). С. $113-116$.

Ананьева Е.В., Каневский П.С. (2016) Брекзит-1 и Брекзит-2: Британия и США меняют парадигму? // Доклады Института Европыл. № 334. Москва: Институт Европы РАН.

Бабынина Л. О. (2016) Значение Brexit для Европейского Союза // Современная Европа. № 4. С. 21-33.

Борко Ю.А. (2003) От европейской идей - к единой Европе. Москва: Издательский Дом “Деловая литература".

Борко Ю.А., Буторина О.В. (2001) От Европейского Союза - к Соединённым Штатам Европы? // Европейский Союз на пороге ХХІ века. Выбор стратегии развития. Москва: УРСС. С. 430-462.

Буховец О.Г. (2008) Эра национализма и особенности образования наций в Европе (часть первая) // Современная Европа. № 4. С. 33-44.

Вайнштейн Г.И. (2009) Европейская идентичность: желаемое и реальное // Полис. Политические исследования. № 4. С. 123-134.

Глинкина С.П., Луконин Д.С. (2002) Проблемы и перспективы включения стран ЦВЕ в систему европейской экономической интеграции // Центральная и Восточная Европа во 2-ой половине 20-ого века, т. 3: Трансформации 90-х годов, часть 1. Москва: Наука.

Громыко Ал.А. (2016) Великобритания: новая политическая ситуация // Современная Европа, № 2, С. $56-60$.

Загорский А.В. (1999) Формирование новой системы межгосударственных отномений в Европе // Современные международные отношения. Разд. ІІІ, гл. 3. Москва: РОССПЭН.

Кавешников Н.Ю. (2004/2005) Конституция Европейского Союза: неопознанный политический объект приближается // Космополис. № 4 (10) С. 33-52.

Любин В. П. (2018) Решающий 2017 год: Политические партии и выборы в Германии // Актуальные проблемы Европы. № 2. С. 37 - 61.

Любин В.П. (2003) Революция миграции и её регулирование. Опыт России, Германии и ЕС в отражении научной литературы и СМИ. URL: http://alestep.narod.ru/lubin/migration.htm (дата обращения: 11.06.18).

Потемкина О.Ю. (2010) Иммиграционная политика Европейского союза. Москва: Русский сувенир.

Потемкина О.Ю. (2015) Миграционный кризис в ЕС: роль стран Вишеградской группы // Современная Европа. № 6. С. 36 -46.

Потемкина О.Ю. (2017) Новые инициативы Евросоюза в сфере урегулирования миграционного кризиса и внутренней безопасности // Европейский Союз: факты и комментарии. № 89. С. 29-34.

Хижный Э.К. (2006) Социально-экономические аспекты расширения ЕС-15 на восток / Европа и становление нового миропорядка // Актуальные проблемы Европы. № 4. С. 164 -185.

\section{References}

Anan'eva E.V. (2016) Migranty v Evrope. Velikobritaniya // Sovremennaya Evropa. No. 2 (68). S. 113-116.

Anan'eva E.V., Kanevskij P.S. (2016) Brekzit-1 i Brekzit-2: Britaniya i SShA menyayut paradigmu?// Doklady Instituta Evropy. No. 334. Moskva: Institut Evropy RAN.

Babynina L.O. (2016) Znachenie Brexit dlya Evropejskogo Soyuza // Sovremennaya Evropa. No. 4. S. 21-33.

Beck U. (2000) The cosmopolitan perspective: sociology of the second age of modernity // British Journal of Sociology. Vol. 51. Issue 1. P. 79-105.

Современная Европа, 2018, №6 
Beck U., Grande E. (2007) Cosmopolitanism. Europe's Way Out of Crisis // European Journal of Social Theory. Vol.10. Issue 1. P. 67-85.

Borko Yu. A. (2003) Ot evropejskoj idej - $k$ edinoj Evrope. Moskva: Izdatel'skij Dom "Delovaya literatura".

Borko Yu. A., Butorina O. V. (2001) Ot Evropejskogo Soyuza - k Soedinennym Shtatam Evropy? // Evropejskij Soyuz na poroge XXI veka. Vybor strategii razvitiya. Moskva: URSS. S. 430-462.

Bruzzone M.G. (2014) "Voto in Europa: la più bassa affluenza nei paesi dell'Est, gli ultimi arrivati". URL: http://www.lastampa.it/2014/05/28/blogs/underblog/voto-in-europa-la-pi-bassa-affluenza-nei-paesidellest-gli-ultimi-arrivati-DYPfebayVPftrhoWtB1ZoL/pagina.html (Accessed 11.06. 2018).

Buras P. (2015) "Polonia: ancora leader della politica estera europea?". URL: http://www.ecfr.eu/rome/post/polonia_leader_rome_office (Accessed 11.06. 2018).

Buxovecz O. G. (2008) Era nacionalizma i osobennosti obrazovaniya nacij v Evrope (chast' pervaya) // Sovremennaya Evropa. No. 4. S. 33-44.

Chabod F. (1967) Storia dell'idea d'Europa, Bari: Laterza.

D'Argenio A. (2016) "Quella torta da 300 miliardi che ha spaccato l'Europa". URL: http://www.repubblica.it/economia/2016/02/20/news/quella_torta_da_300_miliardi_che_ha_spaccato_1_euro pa-133821896/ (Accessed 11.06. 2018).

De Gasperi A. (2009) Scritti e discorsi politici. Vol. 4: Alcide De Gasperi e la stabilizzazione della Repubblica 1948-1954. Bologna: Il Mulino.

De Rougemont D. (1949) Vita o morte dell'Europa. Milano: Edizioni di Comunità.

Delanty G. (2009) The cosmopolitan imagination. Cambridge: Cambridge University Press.

Di Gaspare G. (2012) Teoria e critica della globalizzazione finanziaria. Dinamiche del potere finanziario e crisi sistemiche. Padova: CEDAM.

Diamanti I., "Schengen, la nostra identità in quel trattato. Non può bastare la moneta unica". 25.01.2016. URL: http://www.repubblica.it/esteri/2016/01/25/news/la_nostra_identita_in_quel_ trattato_non_puo_bastare_la_moneta_unica-131980704/ (Accessed 11.06. 2018).

Fabbrini S. (2017) "L'Europa tra incertezza e crisi d'identità". 10.06.2017. URL: http://www.ilsole24ore.com/art/mondo/2017-06-10/l-europa-incertezza-e-crisi-d-identita--

225551.shtml?uuid=AEGjaOcB (Accessed 11.06. 2018).

Feltri V., Sangiuliano G. (2015) Il Quarto Reich. Come la Germania ha sottomesso l'Europa. Milano: Mondadori.

Ferraris L.V. (1998) La "nuova" Germania // Politica internazionale. N. 6. P. 183.

Ferraris L.V. (1999) A dieci anni dal 1989 l'Europa si estende all'Est: un compito per l'Occidente // Politica Internazionale. N. 4-5. P. 14.

Ferrera M. (2014) L'Europa in trappola: come uscirne? // Il Mulino. N.1. PP. 63-76.

Genov N. (1998) Dallo Stato all'individuo: l'Europa dell'Est alla prova // Il Mulino. N. 3. PP. 565-572.

Glinkina S. P., Lukonin D. S. (2002) Problemy i perspektivy vklyucheniya stran CVE v sistemu evropejskoj ekonomicheskoj integracii // Central'naya i Vostochnaya Evropa vo 2-oj polovine 20-ogo veka. T. 3: Transformacii 90-x godov, chast' 1. Moskva: Nauka.

Gromyko Al. A. (2016) Velikobritaniya: novaya politicheskaya situaciya // Sovremennaya Evropa. No.

2. C. $56-60$.

Hayward C. R. (2007) Democracy's Identity Problem: Is "Constitutional Patriotism" the Answer? // Constellations. Vol. 14. No. 2. P. 182-196.

Kaveshnikov N. Yu. (2004/2005) Konstituciya Evropejskogo Soyuza: neopoznannyj politicheskij ob"'ekt priblizhaetsya // Kosmopolis. No. 4 (10). S. 33-52.

Kirchner E. (1993) Unione politica o egemonia tedesca? // Politica Internazionale. N.1. P. 147.

La sentenza della Corte Costituzionale Tedesca Sul Trattato di Lisbona: nota di sintesi. URL: www.senato.it/documenti/repository/.../scheda\%20sintesi\%20sentenza\%20tedesca.pdf. (Accessed 11.06. 2018).

Leoncini F. (2011), a cura di, L'Europa del disincanto. Dal '68 praghese alla crisi del neoliberismo. Soveria Mannelli: Rubbettino.

Ljubin V. P. (2003) Revolyuciya migracii i ee regulirovanie. Opyt Rossii, Germanii i ES v otrazhenii nauchnoj literatury i SMI. URL: http://alestep.narod.ru/lubin/migration.htm (Accessed 11.06. 2018).

Ljubin V. P. (2018) Reshayushhij 2017 god: Politicheskie partii i vybory v Germanii // Aktual'nye problemy Evropy. No. 2. C. 37-61.

Lo Schiavo L. (2009) Immigrazione, cittadinanza, partecipazione: le nuove domande di inclusione nello spazio pubblico. Processi di auto-organizzazione e partecipazione degli immigrati // Quaderni di Intercultura. N. 1. P. $1-18$.

Современная Европа, 2018, №6 
Löwith K. (1999) Il nichilismo europeo. Roma-Bari: Laterza.

Maas W. (2008) Migrants, states, and EU citizenship's unfulfilled promise // Citizenship Studies. Vol.12. P. 583-596.

Mertens T. (2007) Constitutional Patriotism and the European Constitutional Debate in Patriotism: philosophical and political perspectives, ed. I. Primoratz, A. Pavković. Aldershot: Ashgate. P. 113-128.

Milward A.S. (2014) Politics and Purposes in Fifty Years of European Integration // Journal of European History. Vol. 20. P. 43-48.

Muller J.W. (2012) Constitutional patriotism beyond the nation-state: human rights, constitutional necessity, and the limits of pluralism //Cardozo Law Review. Vol. 33. P. 1925-1926.

Pond E. (1992) Germany in the New Europe // Foreign Affairs. Vol. 70, Spring. P. 114-130.

Potemkina O. Yu. (2010) Immigracionnaya politika Evropejskogo soyuza. Moskva: Russkij suvenir.

Potemkina O. Yu. (2015) Migracionnyj krizis v ES: rol' stran Vishegradskoj gruppy // Sovremennaya Evropa. No. 6. C. 36-46.

Potemkina O. Yu. (2017) Novye iniciativy Evrosoyuza v sfere uregulirovaniya migracionnogo krizisa i vnutrennej bezopasnosti // Evropejskij Soyuz: fakty i kommentarii. No. 89. S. 29-34.

Prodi R. (2014) Non era questa l'Europa di De Gasperi e non è questa l'Europa che noi dobbiamo costruire. URL:http://www.romanoprodi.it/interventi/non-era-questa-leuropa-di-de-gasperi-e-non-e-questaleuropa-che-noi-dobbiamo-costruire_8523.html (Accessed 11.06. 2018)

Ratzinger J. (2003) Fede - Verità - Tolleranza. Il Cristianesimo e le Religioni del Mondo. Siena: Cantagalli.

Religious Belief and National Belonging in Central and Eastern Europe 2017. URL: http://www.pewforum.org/2017/05/10/religious-belief-and-national-belonging-in-central-and-eastern-europe/ (Accessed 11.06. 2018)

Romano S. (1994) La Germania e l'Europa: niente di nuovo sul fronte occidentale // Il Mulino/Europa. Bologna. N. 2. P. 53-56.

Schlesinger Ph. (2007) A Cosmopolitan Temptation // European Journal of Communication. Vol. 22. P. 413-426.

Taylor P. (1996) The European Union in 1990's. New York: Oxford University Press.

Vainshtein G.I. (2009) Evropeyskaya identichnost': zhelaemoe i real'noe // Polis. Politicheskiye issledovaniya. No. 4. S. 123-134.

Waldemberg M. (1998) Democrazia e problemi nazionali nell'Europa centro-orientale // Petrovic R., Russo F. (a cura di ) L'altra europa. L'Europa centrale e i Balcani verso l'Unione Europea. Napoli: ESI. P. $61-69$.

Xizhnyj E. K. (2006) Social'no-ekonomicheskie aspekty rasshireniya ES-15 na vostok / Evropa i stanovlenie novogo miroporyadka // Aktual'nye problemy Evropy. No.4. S. 164-185.

Zagorskij A. V. (1999) Formirovanie novoj sistemy mezhgosudarstvennyx otnoshenij v Evrope // Sovremennye mezhdunarodnye otnosheniya. Razd. III, gl. 3. Moskva: ROSSPEN.

\section{EU political identity: new paradigms, old problems}

Author: Alonzi R., PhD in History of International Relations, qualified as associate professor in the Italian higher education system, contract professor at the Unicollege Florence, visiting professor at the National Research University HSE, PhD student at the Department of Comparative Politics, RUDN University. Address: Miklukho-Maklaya str., 17/1, Moscow, Russia. E-mail: alonziroberta@ gmail.com

Abstract. The article is dedicated to the analysis of the controversial question of European political identity. The issue of conceptualizing the European identity is connected to the necessity of achieving a common European political and geographical dimension. The research explores the reasons for the lack of shared acceptance of a general idea about the political dimension and the future of the community by the EU members. By arguing that the European identity-building process rests on the concepts of centrality of the individual in society and Christianity as a model of civilizational development and socio-cultural integration, the author demonstrates that the essence of a united Europe is not only pluralistic but universalistic. Consequently, it is necessary to rethink the nature of the European Union.

Key words: European Union, political identity, post-national state, Eastern Europe, migration processes, Christianity, EU Constitution.

DOI: http://dx.doi.org/10.15211/soveurope62018142151

Современная Европа, 2018, №6 